\title{
The phenomenology of pain in Parkinson's disease
}

\author{
José Antonio Camacho-Conde ${ }^{1}$ and Víctor Manuel Campos-Arillo ${ }^{2}$ \\ 'Department of Psychobiology and Methodology of Behavioral Sciences, University of Malaga, Malaga, Spain \\ ${ }^{2}$ Movement Disorders Unit, Vithas Xanit International Hospital, Benalmadena, Spain
}

Received September 2, 2019

Revised November 28, 2019

Accepted December 2, 2019

\section{Correspondence}

José Antonio Camacho-Conde

Department of Psychobiology and

Methodology of Behavioral Sciences,

University of Malaga, Campus de

Teatinos, Bulevar Louis Pasteur, 25,

29071 Malaga, Spain

Tel: +34-952-137-279

Fax: +34-952-137-270

E-mail: jacamacho@uma.es

José Antonio Camacho-Conde's current affiliation: Department of Medicine and Dermatology, Faculty of Medicine, University of Malaga, Malaga, Spain
Background: Parkinson's disease (PD) is a neurodegenerative disorder that is the second most common disorder after Alzheimer's disease. PD includes both "motor" and "non-motor" symptoms, one of which is pain. The aim of this study was to investigate the clinical characteristics of pain in patients with PD.

Methods: This cross-sectional study included 250 patients diagnosed with PD, $70 \%$ of which had mild to moderate PD (stages 2/3 of Hoehn and Yahr scale). The average age was 67.4 years, and the average duration since PD diagnosis was 7.1 years. Relevant data collected from PD patients were obtained from their personal medical history.

Results: The prevalence of pain was found to be high (82\%), with most patients $(79.2 \%)$ relating their pain to PD. Disease duration was correlated with the frequency of intense pain (R: 0.393; $P<0.05$ ). PD pain is most frequently perceived as an electrical current $(64 \%)$, and two pain varieties were most prevalent $(2.60 \pm 0.63)$. Our findings confirm links between pain, its evolution over time, its multi-modal character, the wide variety of symptoms of PD, and the female sex.

Conclusions: Our results demonstrated that the pain felt by PD patients is mainly felt as an electrical current, which contrasts with other studies where the pain is described as burning and itching. Our classification is innovative because it is based on anatomy, whereas those of other authors were based on syndromes.

Key Words: Cross-Sectional Studies; Dopaminergic Neurons; Neurodegenerative Diseases; Pain; Pain Measurement; Parkinson Disease; Prevalence; Syndrome

\section{INTRODUCTION}

Pain is a common non-motor symptom of Parkinson's disease (PD) patients, is often associated with depression [1], induces poorer health-related quality of life [2] and impairs patient autonomy [3]. Valuations on its impact vary from $29 \%$ [4] to $85 \%$ [5], although we can assert that it represents an important issue for the majority of PD patients. Oddly enough, there are virtually no peer reviews [6] and no extended monographs published on the treatment of non-motor symptoms by the Movement Disorder Society that are based on evidence [7]. PD is clearly established when neuronal loss within the compact area of the substantia nigra reaches $60 \%$ to $70 \%$ and when dopamine inside the striatum is approximately $80 \%$ compared to normal controls. In its initial stages (i.e., the pre-motor stage), some unusual non-motor symptoms may be present that progress into motor symptoms over time (i.e., the motor stage).

Manifest symptoms during the pre-motor stage include depression, pain, hyposmia (reduced sense of smell), constipation, rapid eye movement sleep behavior disor- (a) This is an open-access article distributed under the terms of the Creative Commons Attribution Non-Commercial License (http://creativecommons.org/licenses/by-nc/4.0/), which permits unrestricted non-commercial use, distribution, and reproduction in any medium, provided the original work is properly cited.

(C) The Korean Pain Society, 2020
Author contributions: José Antonio Camacho-Conde: Investigation; Víctor Manuel Campos-Arillo: Supervision. 
ders, and seborrheic dermatitis [8]. During this particular phase, when facing stress, patients may also show transitory motor symptoms like slight intermittent and asymmetric movements of the limbs, lack of gestures and expressions, tiredness, or perspiration issues during heat waves [9]. During the preclinical stage, pain is one of the early symptoms of PD. Primary pain [10] or secondary pain may be due to lack of physical activity. Occasionally, pain can affect one shoulder, which is why many patients are mistakenly diagnosed with "painful shoulder syndrome".

Approximately $25 \%$ of patients show pain-related (throbbing or uncomfortable) sensations in different body areas. These types of PD-associated pains have been classified as central pain, with some possible alterations of the intralaminar nuclei circuits inside the thalamus itself (because they may be affected by the disease), and as ascendant sensitive systems (discriminatory and palpable perceptions) that may be related to an unadapted motor-based response [11]. At least two-thirds of PD patients report feeling pain to some degree [12]; the etiology of this pain appears to rely on multiple factors. Pain is present during the endstages of PD, which includes dyskinesias, dystonias, offperiods, and central nervous system-sensitive disorders. Pain is one of the disorders that most significantly affects quality of life [13]. The aim of this study was to investigate the clinical characteristics of pain in patients with PD.

\section{MATERIALS AND METHODS}

\section{Participants}

A total of 250 patients diagnosed with PD were included in this cross-sectional study. Inclusion criteria were as follows: patients of either sex, aged $\geq 30$; with a previous idiopathic PD diagnosis; with one permanent, full-time caregiver; and who provided informed consent to participate in the study. Exclusion criteria included noncompliance to one of the inclusion criteria, and a medical or psychiatric comorbidity precluding an accurate evaluation of PD. Patients included in the present study were then "newlydiagnosed" patients, or considered patients with idiopathic PD according to the criteria established by the UK Parkinson's Disease Society Brain Bank for PD stages I-IV.

\section{Methodology}

The study protocol was reviewed and approved by the Vithas Xanit International Hospital Ethics Committee (IRB No. 11-348). Participants were recruited from the hospital's neurology department and signed an informed consent form prior to inclusion in the study. A neurologist and a neuropsychologist belonging to the movement disorders unit of the neurosciences area of the aforementioned hospital evaluated patients prior to their inclusion. Relevant data collected from PD patients were obtained from their personal medical history.

We used the following scales: The scales for outcomes in Parkinson's disease (SCOPA)-motor [14], SCOPA-AUT (autonomic) [15,16], SCOPA-COG (cognition) [17,18], modified Parkinson's psychosis rating scale [19], Hoehn and Yahr [20], and the hospital anxiety and depression scale [21]. We also included "visual analogue scale" (VAS) testing because of its ease of use, which was quickly adapted to measure pain intensity. A 24-item questionnaire, previously used by the Santos-García et al. [3] research group to evaluate pain types was used to identify, classify, and analyse pain; a ready-to-select pain-type list is included in this questionnaire. We believe that the inclusion of such different pain-types and frequencies over time is a rather unique advantage of our study.

Data were analysed with IBM SPSS ver. 22.0 (IBM Corp., Armonk, NY) and quantitative variables are expressed as means \pm standard deviation, or with the absolute frequency (percentages). Spearman's correlation coefficient was also used to measure the strength of association between some quantitative random variables. $P<0.05$ was considered statistically significant.

\section{RESULTS}

We included 250 patients with PD whose clinical and epi-

Table 1. Basic Sample Characteristics $(n=250)$

\begin{tabular}{llr}
\hline \multicolumn{1}{c}{ Characteristic } & \multicolumn{2}{c}{ Value } \\
\hline Sex & Male & $110(44.0)$ \\
& Female & $140(56.0)$ \\
Mean age (yr) & & $67.4 \pm 10.1(44-87)$ \\
Civil status & Married/partner & $170(68.0)$ \\
& Single/widower & $60(24.0)$ \\
& Divorced & $10(4.0)$ \\
Environment & Own residence & $240(96.0)$ \\
Surroundings & State centres & $10(4.0)$ \\
& Urban & $200(80.0)$ \\
Educational attainment & Rural & $50(20.0)$ \\
Age of PD onset (yr) & Primary school & $150(60.0)$ \\
PD duration (yr) & Secondary school & $100(40.0)$ \\
HADS & & $58.0 \pm 11.9(24-85)$ \\
& Depression & $7.1 \pm 5.8(1-45)$ \\
& No depression & $180(72.0)$ \\
\hline
\end{tabular}

Values are presented as number (\%) or mean \pm standard deviation (range). PD: Parkinson's disease, HADS: hospital anxiety and depression scale. 
demiological data are summarized in Table 1. The prevalence of pain in these patients was found to be $82 \%$. Distributions following the Hoehn and Yahr classification were as follows: stage $1(23.8 \%)$, stage $2(49.4 \%)$, stage $3(20.4 \%)$, stage $4(4.7 \%)$, and stage $5(0.7 \%)$. The following treatment distributions were observed during the initial treatment phase: levodopa (L; 35.4\%), dopaminergic agonist (DA; $33.7 \%)$, polypharmacy $(10.8 \%)$, other treatment $(9.3 \%)$, and lastly, L supplemented with agonists (7.1\%).

With respect to the initial motor situation of PD patients during their first evaluation, we assumed the non-fluctuants to be in an "on stage", and included the fluctuants into an "on" or "off" group according to the study protocol. Under these premises, approximately $96 \%$ were considered as "on" patients and $4 \%$ as "off" patients. Table 2 shows the descriptive statistics derived from the scales used in the study.

Pain experienced by PD patients is mainly represented

Table 2. Health Characteristics of the Sample $(n=250)$

\begin{tabular}{lc}
\hline \multicolumn{1}{c}{ Scale } & Value \\
\hline Total SCOPA-motor & $25.04 \pm 13.50(6-54)$ \\
Motor exploration & $12.75 \pm 5.49(3-22)$ \\
Daily activities & $8.16 \pm 4.43(1-18)$ \\
Motor complications & $2.48 \pm 2.34(0-7)$ \\
Total SCOPA-AUT & $23.58 \pm 14.18(2-65)$ \\
Total SCOPA-COG & $23.06 \pm 7.35(3-35)$ \\
MPPRS & $2.50 \pm 2.00(0-7)$ \\
Hoehn and Yahr & $2.56 \pm 0.87(1-5)$ \\
HADS & $16.48 \pm 8.61(0-38)$ \\
Total pain & $38.08 \pm 26.96(0-100)$ \\
\hline
\end{tabular}

Values are presented as mean \pm standard deviation (range). SCOPA: the scales for outcomes in Parkinson's disease, AUT: autonomic, COG: cognition, MPPRS: modified Parkinson's psychosis rating scale, HADS: hospital anxiety and depression scale.

Table 3. Pain Types Frequencies

\begin{tabular}{lc}
\hline \multicolumn{1}{c}{ Pain types } & Value \\
\hline Generalized & $0.52 \pm 1.80$ \\
Hot and cold & $0.60 \pm 1.80$ \\
Palpitations & $0.12 \pm 0.33$ \\
Itching & $0.04 \pm 0.20$ \\
Oppressive & $0.24 \pm 0.43$ \\
Colicky & $0.00 \pm 0.00$ \\
Weakness, drowsiness & $0.24 \pm 0.43$ \\
Numbness, tingling & $0.40 \pm 0.50$ \\
Burning & $0.16 \pm 0.37$ \\
Internal & $0.40 \pm 0.50$ \\
Tension & $0.32 \pm 0.47$ \\
Throbbing & $0.52 \pm 0.51$ \\
Electrical discharge & $0.64 \pm 1.80$
\end{tabular}

Values are presented as mean \pm standard deviation. by the electrical current type (64\%) and the itching type (4\%). These results have been drawn from PD patients' answers to item 21 of the pain questionnaire (Table 3 ). The frequency of these pain types was found to be the following: patients feeling only one (12\%), two (16\%), or three (72\%)-Some PD patients responded feeling three or more pain types. Answers were classified under three categories only because we believed that differentiating over three types would be too complicated-different pain types ( 2.60 \pm 0.63 ) [3-5]. PD pain differ between the sexes in paintype frequency: females (1 type: 14.28\%; 2 types: $7.14 \%$; 3 types: $78.57 \%$ ), males (1 type: $9.09 \%$; 2 types: $27.27 \%$; 3 types: $63.63 \% ; n=250$; mean: 2.60; Fig. 1). There is a higher prevalence of one singular pain type in females than in males; however, males present a higher frequency of two pain types than do females.

Quantitative pain perception in PD patients provides data on pain frequency and shows some intense pain (VAS score: $55.6 \pm 29.3$ ) with quite frequent events. Pain intensity was also evaluated (mean: $61.00 \pm 21.54)$. Gradual pain characteristics are shown in percentages in Fig. 2.

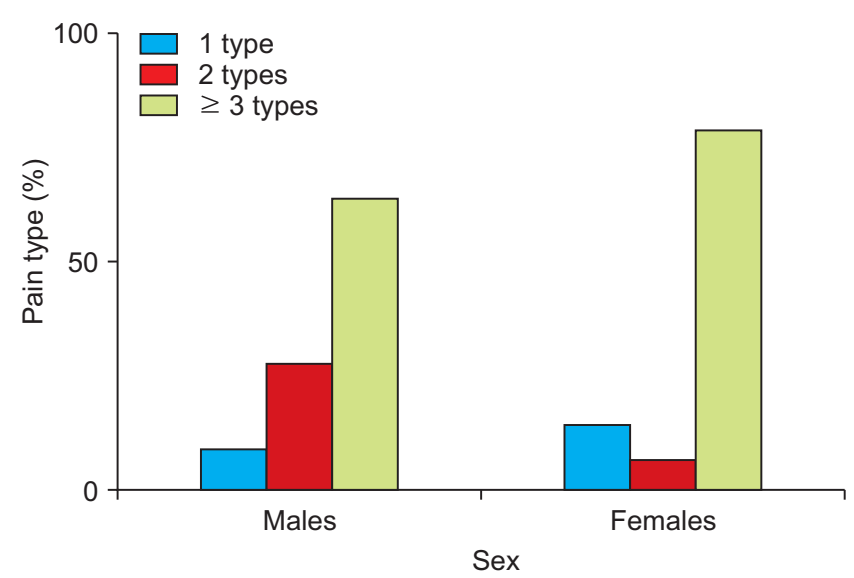

Fig. 1. The frequency of pain types according to sex.

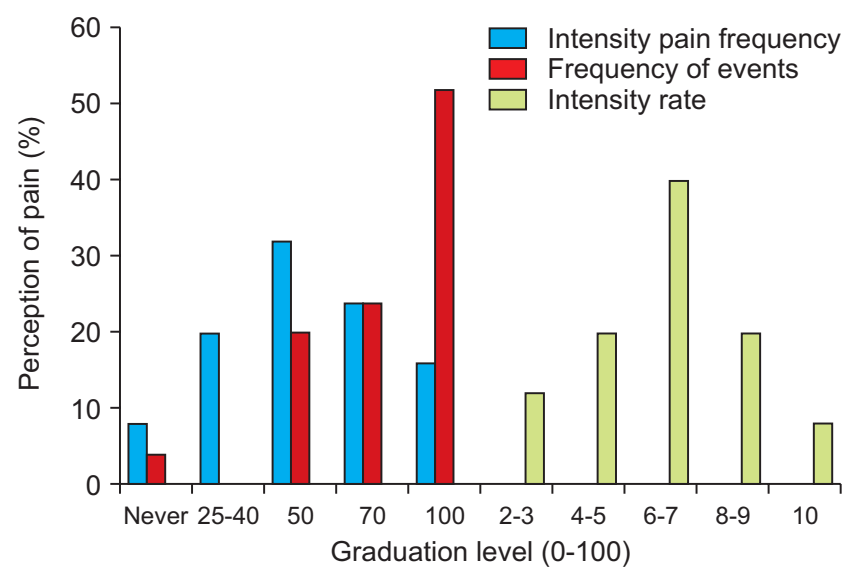

Fig. 2. Gradual pain characteristics $(n=250)$. 


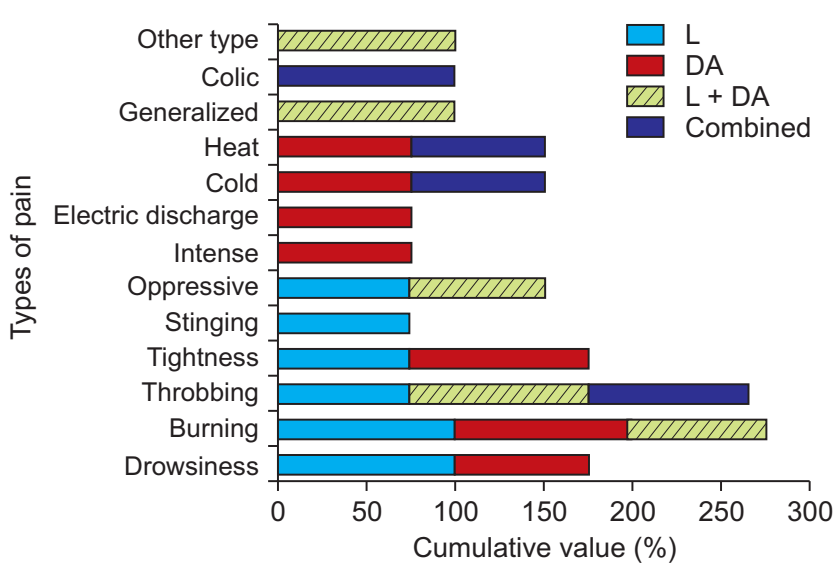

Fig. 3. The pain types according the medications $(n=250)$. L: levodopa, DA: dopaminergic agonist.

PD duration was also found to be linked to the frequency of intense pain $(\mathrm{R}=0.393 ; P<0.05)$. To summarize, it seems that disease duration is a crucial determinant of pain severity. With results obtained from answers to item 11 of the questionnaire, dopaminergic treatment can be confirmed as an efficient intervention to control pain in only $48 \%$ of patients. PD patients that fail to respond to dopaminergic treatments to mitigate their pain are often administered general analgesics to positive effect: standard analgesic treatments were found to reduce participants' pain in $78.8 \%$ of cases.

Another interesting fact is that PD patients feel pain in different ways depending on the implementation of the dopaminergic treatment. All patients feel some burning pain when administered L and DA. When treatments are combined, patients feel an increase in throbbing and electrical discharge-like pain. We have only included the percentages ranging from $75 \%-100 \%$ (Fig. 3) for the L, DA, $\mathrm{L}+\mathrm{DA}$, and combined treatments.

Most patients (79.2\%) assert that their pain is related to their PD, while $20.8 \%$ say it has nothing to do with it. Our results show that PD patients who feel pain are those that have been suffering from PD for over three months (3.72 \pm $0.79 \mathrm{mo}$ ). Approximately $32 \%$ of patients felt pain prior to their PD diagnosis, and approximately $60 \%$ of patients had already reported their pain to their neurology specialists.

With regard to the body areas affected by pain, $84 \%$ of patients localize it to the lower back area, with $27 \%$ of these feeling some kind of descending cramp pain towards the lower limbs. The average number of painful areas reported by PD patients was three. Pain located in different body areas was present in $20 \%-60 \%$ of cases, with the highest prevalence felt in the back and lower limbs (Fig. 4).

We added some supplementary statistics regarding the body areas most affected by pain in PD patients based on the Hoehn and Yahr classification [20]. The early stages

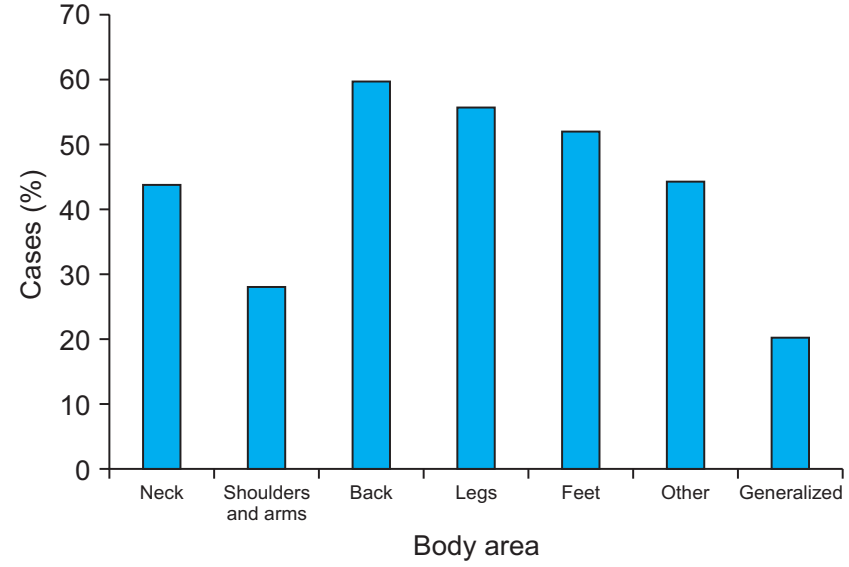

Fig. 4. The most painful regions in patients with Parkinson's disease.

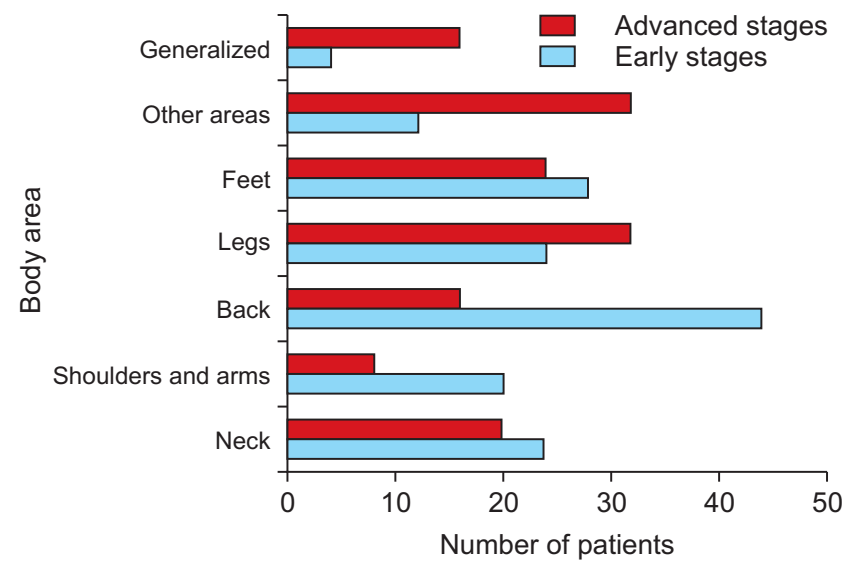

Fig. 5. Body area distribution of pain and stage of Parkinson's disease.

include phases I and II, and the advanced stages include phases III-V (Fig. 5).

PD patients reported higher pain levels in their most PD-affected body areas. Approximately $84 \%$ of participants in the study reported feeling pain when they were more stationary, still, clumsier, stiffer, or shakier, which is when they were more affected by some kind of motorrelated alteration. PD-related pain surfaces at different times throughout the day. Our results reveal that some PD patients felt pain constantly (28\%), some when they were clumsier or "off" (36\%) - which is when they are more affected by their PD-and some intermittently throughout the day (24\%). Thirty-two percent of the PD patients in our study experienced pain throughout the entire day, $24 \%$ during the night, and $16 \%$ early in the morning or at another time point. Approximately $60 \%$ of participants reported feeling pain, including pressure in one of their upper or lower limbs, when their muscles or joints felt stiffer, while $40 \%$ of them reported no correlation with stiffness. Approximately $76 \%$ of PD patients felt pain during dyskinesia events, while $24 \%$ did not. 


\section{DISCUSSION}

The prevalence of pain in our study $(82 \%)$ is quite similar to findings of other studies [3,22-27], since minor prevalence data analysis must consider the number of cases included [28]. Our results, however, differ from those of some studies, such as Djaldetti et al. [29], where the main pain is described as burning and itching. However, their results did corroborate ours with respect to the prevalence of the burning type of pain in PD patients.

A review of the literature found no detailed analysis of the perceived pain [30-34]; most studies do not account extensively for these aspects [35]. Some studies, however, have described pain using a much more syndrome-based terminology, which is interpreted by researchers and specialists in a quite similar way as that used for the advanced stages, namely musculoskeletal $(70 \%)$, dystonic $(40 \%)$, radicular neuropathic $(20 \%)$, and central neuropathic $(10 \%)$ [23]. Yet, in the reviews published thus far, the most frequent descriptions of PD patients' pain reflect some form of continuous "burning", "itching", "stabbing", "aching", or "tingling" sensation [23,27,29-31], which explains our use of this terminology in our study. These previous works, and ours, have generally focussed on the representation and importance of the alterations of the senses described herein. Furthermore, we, like they, have found pain to be most commonly located in the motor areas most affected by PD, particularly during the off-period, with no specific explorable deficit in the senses, whether dermatome-limited or neurologically diffuse.

PD patients can feel different types of pain. In this study, we quantified the frequency of these different types of pain after studying the answers to item 21 in the pain questionnaire. PD patients who feel pain experience between one and three (or more) types of pain. According to our results, the female sex is more highly associated with pain in PD. This had already been shown in previous studies [22] where being female acted as an independent predictor of pain. In other, less exhaustive studies, no correlation was found between pain and sex [27,31-33], age, evolution over time, or motor stage [22,31]. As previously mentioned, our classification is based on anatomy (because that is how patients refer to their pain), whereas those of other authors is based on syndromes (as referred to by the specialists, so that patients "learn to decipher" their pain). Wasner and Deuschl [36] recommended that pain be classified as either nociceptive (musculoskeletal, visceral, or cutaneous) or neuropathic (peripheral or central). On the other hand, Chaudhuri and Schapira [37] differentiated the types of pain as follows: musculoskeletal pain, chronic pain related to $\mathrm{PD}$, pain related to fluctuations, nighttime pain, orofacial pain, pain affecting peripheral extremities, and abdominal pain. The pain classification established by Ford [38] remains one of the more commonly mentioned, because it identifies five fundamental types of pain in PD that are based on origin and on treatment perspective. Valkovic et al. [34] recently classified pain in PD into five categories using a syndrome-based classification. Our study holds a particular strength because it used a clinical classification that resembles much more closely the sensations described by the patients themselves.

As concerns the time of day when PD patients were most aware of their pain, we should point out that none of our patients explicitly expressed feeling pain early in the morning, which conflicts with the idea that fluctuationdenominated "early-morning dystonia" is painful. PD patients feeling pain indicated its presence as constant throughout the day (32\%) or as occurring at nighttime (24\%), when waking up (12\%), in the afternoon (8\%), in the morning and afternoon (84\%), in the afternoon and evening (4\%), and while waking up combined with another time during the day (16\%). New treatments used to treat PD are now available that may help alleviate these symptoms due to the glutamate action-based mechanisms, like that of safinamide, which has a dual action (monoamine oxidase B inhibitor and glutamate) [39].

To conclude, these results suggest that pain has a substantial impact on the motor and non-motor aspects of patients with PD regardless of the clinical characteristics of the pain. Dopaminergic treatment proved quite effective to control pain in approximately half of these patients. The present study confirms an existing link between pain, its evolution over time, the female gender, its multi-modal character, and PD's wide variety of symptoms. Our results demonstrated that the pain perceived by PD patients is mainly described as a type of electrical current, and least frequently described as a type of itching, compared to other studies where the pain was described as a burning and itching sensation. Our classification is comparatively more innovative because it is anatomy-based, whereas those of other authors are syndrome-based. Furthermore, based on the results of this study and of previous studies, pain was significantly influenced by depression and parkinsonian motor impairment.

\section{CONFLICT OF INTEREST}

No potential conflict of interest relevant to this article was reported. 


\section{FUNDING}

No funding to declare.

\section{ORCID}

José Antonio Camacho-Conde, https://orcid.org/0000-0002-6912-8462 Víctor Manuel Campos-Arillo, https://orcid.org/0000-0003-3621-0782

\section{REFERENCES}

1. Lee HJ, Choi EJ, Nahm FS, Yoon IY, Lee PB. Prevalence of unrecognized depression in patients with chronic pain without a history of psychiatric diseases. Korean J Pain 2018; 31: 11624.

2. Roh JH, Kim BJ, Jang JH, Seo WK, Lee SH, Kim JH, et al. The relationship of pain and health-related quality of life in Korean patients with Parkinson's disease. Acta Neurol Scand 2009; 119: 397-403.

3. Santos-García D, Abella-Corral J, Aneiros-Díaz A, SantosCanelles H, Llaneza-González M, Macías-Arribi M. [Dolor en la enfermedad de Parkinson: prevalencia, características, factores asociados y relación con otros síntomas no motores, calidad de vida, autonomía y sobrecarga del cuidador]. Rev Neurol 2011; 52: 385-93. Spanish.

4. Martinez-Martin P, Rodriguez-Blazquez C, Kurtis MM, Chaudhuri KR; NMSS Validation Group. The impact of nonmotor symptoms on health-related quality of life of patients with Parkinson's disease. Mov Disord 2011; 26: 399-406.

5. Lee MA, Walker RW, Hildreth TJ, Prentice WM. A survey of pain in idiopathic Parkinson's disease. J Pain Symptom Manage 2006; 32: 462-9.

6. Goldman JG, Postuma R. Premotor and nonmotor features of Parkinson's disease. Curr Opin Neurol 2014; 27: 434-41.

7. Seppi K, Weintraub D, Coelho M, Perez-Lloret S, Fox SH, Katzenschlager R, et al. The Movement Disorder Society evidence-based medicine review update: treatments for the non-motor symptoms of Parkinson's disease. Mov Disord 2011; 26 Suppl 3: S42-80.

8. Bodis-Wollner I. Neuropsychological and perceptual defects in Parkinson's disease. Parkinsonism Relat Disord 2003; 9 Suppl 2: S83-9.

9. Lees AJ. When did Ray Kennedy's Parkinson's disease begin? Mov Disord 1992; 7: 110-6.

10. Koller WC. Sensory symptoms in Parkinson's disease. Neurology 1984; 34: 957-9.

11. Zia S, Cody FW, O’Boyle DJ. Discrimination of bilateral differences in the loci of tactile stimulation is impaired in subjects with Parkinson's disease. Clin Anat 2003; 16: 241-7.

12. Page DB, Weaver F, Wilkie DJ, Simuni T. A computerized sur- vey of pain in Parkinson's disease patients: a pilot feasibility study. Parkinsonism Relat Disord 2010; 16: 139-41.

13. Martinez-Martin P, Deuschl G. Effect of medical and surgical interventions on health-related quality of life in Parkinson's disease. Mov Disord 2007; 22: 757-65.

14. Marinus J, Visser M, Stiggelbout AM, Rabey JM, MartínezMartín P, Bonuccelli U, et al. A short scale for the assessment of motor impairments and disabilities in Parkinson's disease: the SPES/SCOPA. J Neurol Neurosurg Psychiatry 2004; 75: 388-95.

15. Visser M, Marinus J, Stiggelbout AM, Van Hilten JJ. Assessment of autonomic dysfunction in Parkinson's disease: the SCOPA-AUT. Mov Disord 2004; 19: 1306-12.

16. Rodriguez-Blazquez C, Forjaz MJ, Frades-Payo B, de PedroCuesta J, Martinez-Martin P; Longitudinal Parkinson's Disease Patient Study; Estudio Longitudinal de Pacients con Enfermedad da Parkinson Group. Independent validation of the scales for outcomes in Parkinson's disease-autonomic (SCOPA-AUT). Eur J Neurol 2010; 17: 194-201.

17. van Hilten JJ, van der Zwan AD, Zwinderman AH, Roos RA. Rating impairment and disability in Parkinson's disease: evaluation of the unified Parkinson's disease rating scale. Mov Disord 1994; 9: 84-8.

18. Martínez-Martín P, Frades-Payo B, Rodríguez-Blázquez C, Forjaz MJ, de Pedro-Cuesta J, ELEP G, et al. Atributos psicométricos de la scales for outcomes in Parkinson's diseasecognition (SCOPA-Cog), versión en castellano. Rev Neurol 2008; 47: 337-43.

19. Friedberg G, Zoldan J, Weizman A, Melamed E. Parkinson psychosis rating scale: a practical instrument for grading psychosis in Parkinson's disease. Clin Neuropharmacol 1998; 21: 280-4.

20. Hoehn MM, Yahr MD. Parkinsonism: onset, progression, and mortality. 1967. Neurology 1998; 50: 318.

21. Bjelland I, Dahl AA, Haug TT, Neckelmann D. The validity of the hospital anxiety and depression scale. An updated literature review. J Psychosom Res 2002; 52: 69-77.

22. Barone P, Antonini A, Colosimo C, Marconi R, Morgante L, Avarello TP, et al.; PRIAMO Study Group. The PRIAMO study: a multicenter assessment of nonmotor symptoms and their impact on quality of life in Parkinson's disease. Mov Disord 2009; 24: 1641-9.

23. Beiske AG, Loge JH, Rønningen A, Svensson E. Pain in Parkinson's disease: prevalence and characteristics. Pain 2009; 141: $173-7$.

24. Quittenbaum BH, Grahn B. Quality of life and pain in Parkinson's disease: a controlled cross-sectional study. Parkinsonism Relat Disord 2004; 10: 129-36.

25. Cury RG, Galhardoni R, Fonoff ET, Dos Santos Ghilardi MG, Fonoff F, Arnaut D, et al. Effects of deep brain stimulation on pain and other nonmotor symptoms in Parkinson disease. Neurology 2014; 83: 1403-9. 
26. Broen MP, Braaksma MM, Patijn J, Weber WE. Prevalence of pain in Parkinson's disease: a systematic review using the modified QUADAS tool. Mov Disord 2012; 27: 480-4.

27. Defazio G, Berardelli A, Fabbrini G, Martino D, Fincati E, Fiaschi A, et al. Pain as a nonmotor symptom of Parkinson disease: evidence from a case-control study. Arch Neurol 2008; 65: 1191-4.

28. Nègre-Pagès L, Regragui W, Bouhassira D, Grandjean H, Rascol O; DoPaMiP Study Group. Chronic pain in Parkinson's disease: the cross-sectional French DoPaMiP survey. Mov Disord 2008; 23: 1361-9.

29. Djaldetti R, Shifrin A, Rogowski Z, Sprecher E, Melamed E, Yarnitsky D. Quantitative measurement of pain sensation in patients with Parkinson disease. Neurology 2004; 62: 2171-5.

30. Schestatsky P, Kumru H, Valls-Solé J, Valldeoriola F, Marti MJ, Tolosa E, et al. Neurophysiologic study of central pain in patients with Parkinson disease. Neurology 2007; 69: 2162-9.

31. Tinazzi M, Del Vesco C, Fincati E, Ottaviani S, Smania N, Moretto G, et al. Pain and motor complications in Parkinson's disease. J Neurol Neurosurg Psychiatry 2006; 77: 822-5.

32. Hanagasi HA, Akat S, Gurvit H, Yazici J, Emre M. Pain is common in Parkinson's disease. Clin Neurol Neurosurg
2011; 113: 11-3.

33. Rana AQ, Kabir A, Jesudasan M, Siddiqui I, Khondker S. Pain in Parkinson's disease: analysis and literature review. Clin Neurol Neurosurg 2013; 115: 2313-7.

34. Valkovic P, Minar M, Singliarova H, Harsany J, Hanakova M, Martinkova J, et al. Pain in Parkinson's disease: a crosssectional study of its prevalence, types, and relationship to depression and quality of life. PLoS One 2015; 10: e0136541.

35. Truini A, Frontoni M, Cruccu G. Parkinson's disease related pain: a review of recent findings. J Neurol 2013; 260: 330-4.

36. Wasner G, Deuschl G. Pains in Parkinson disease--many syndromes under one umbrella. Nat Rev Neurol 2012; 8: 28494.

37. Chaudhuri KR, Schapira AH. Non-motor symptoms of Parkinson's disease: dopaminergic pathophysiology and treatment. Lancet Neurol 2009; 8: 464-74.

38. Ford B. Pain in Parkinson's disease. Mov Disord 2010; 25 Suppl 1: S98-103.

39. Cattaneo C, Barone P, Bonizzoni E, Sardina M. Effects of safinamide on pain in fluctuating Parkinson's disease patients: a post-hoc analysis. J Parkinsons Dis 2017; 7: 95-101. 